\title{
Clostridium perfringens and other anaerobes isolated from bile
}

\author{
YOSHIAKI SAKAGUCHI, KENJIRO MURATA, MASAHIDE KIMURA* \\ From the Department of Clinico-Laboratory Medicine, and the * Central Laboratory, Kansai Medical University \\ Hospital, 1 Fumizono-cho, Moriguchi-shi, Osaka, Japan 570
}

SUMMARY Clostridium perfringens was isolated from bile in 13 cases of 150 patients examined. The serotypes of $C$ perfringens strains isolated from bile and faeces were investigated using antisera to Hobbs' type 1-17. Two or more serological types were often found in a single specimen, but in the same patient the serotypes of $C$ perfringens strains isolated from the bile were identical with those from the faeces.

Beta-glucuronidase production in these $C$ perfringens serotypes was tested with the API-Strep system. Strains agglutinated with Hobbs' antisera produced $\boldsymbol{\beta}$-glucuronidase, but non-agglutinated strains did not.

The presence of bacteria in the bile from gallbladder or duct is thought to be evidence of biliary tract infection. Bacteria isolated from bile collected by duodenal aspiration are often the target of chemotherapy.

There have been many reports on aerobes in the bile, especially Gram-negative rods such as $E$ coli, Klebsiella, and Enterobacter. ${ }^{1}$

In this paper, we classified the anaerobes isolated from 150 patients' bile as to species, and in each of the 13 cases of $C$ perfringens, the strain was serotyped with Hobbs' antisera. We are interested in whether $C$ perfringens, now firmly established as an important cause of food poisoning, also plays a role in gallstone formation. It has been suggested by Maki that $\beta$-glucuronidase may catalyse the hydrolysis of bilirubin glucuronide into free bilirubin and glucuronic acid, and that the free bilirubin may then combine with calcium to form insoluble salts. ${ }^{2}$ Bacterial $\boldsymbol{\beta}$-glucuronidase was extensively studied in the aerobes $E$ coli, Streptococcus pyogenes, Staphylococcus albus, and Shigella,,$^{3-6}$ but that of anaerobes has not yet been studied. Therefore we investigated $\beta$-glucuronidase production in $C$ perfringens from bile.

\section{Material and methods}

Two hundred and seventy-nine specimens from 150 subjects were received at the Bacteriology Department of the Central Laboratory of Kansai

Accepted for publication 4 October 1982
Medical University Hospital between May 1981 and April 1982. These specimens were cultured both aerobically and anaerobically.

Gifu Anaerobic Medium (GAM) agar (Nissui Co, Tokyo, Japan) with egg-yolk, and Phenylethylalcohol agar (Nikken Co, Kyoto, Japan) were used for anaerobic culture. Horse-blood agar (Eiken Co, Tokyo, Japan) and MacConkey agar (Eiken) were used for aerobic culture. After inoculation of a bile sample, aerobic cultures were incubated for $24 \mathrm{~h}$ and anaerobic cultures for $48 \mathrm{~h}$, at $37^{\circ} \mathrm{C}$. Anaerobic cultures were grown in an anaerobic culture system (Forma Scientific Co, USA), in which an absolute anaerobic atmosphere can be achieved by evacuation and replacement of the air with a mixture of $80 \% \mathrm{~N}_{2}$, $10 \% \mathrm{H}_{2}$, and $10 \% \mathrm{CO}_{2}$.

Bacterial morphology was checked by Gram's stain, and colonies were transferred to two plates of egg-yolk GAM agar. One plate was cultured anaerobically, and the other aerobically. Alpha toxin (lecithinase) production was detected by opalescence around colonies on egg-yolk agar.

The strains from blood agar or egg-yolk plates were typed into the known Hobbs' serotypes 1-17 by slide agglutination tests using heat-stable $C$ perfringens type A antisera for diagnosis (Denka-Seiken, Tokyo, Japan). ${ }^{78}$ The reference strain of $C$ perfringens (GAI 0084) was obtained from Gifu University, Gifu, Japan. Identification of anaerobes was performed with an API-20 A system (API Laboratory Products Ltd, France) with reference to the VPI Anaerobe laboratory manual. ${ }^{9}$

For the detection of $\beta$-glucuronidase activity, 
Table 1 Anaerobes isolated from bile

\begin{tabular}{lc}
\hline Species & $\begin{array}{c}\text { No of } \\
\text { strains }\end{array}$ \\
\hline Cocci & \\
Veillonella parvula & 10 \\
Peptostreptococcus anaerobius & 7 \\
Peptostreptococcus productus & 2 \\
Peptostreptococcus lanceolatus & 1 \\
Peptococcus aerogenes & 3 \\
Peptococcus anaerobius & 1 \\
Peptococcus prevoti & 4 \\
Streptococcus intermedius & 2 \\
Streptococcus constellatus & 3 \\
Streptococcus morbillorum & 2 \\
Total & 36
\end{tabular}

Gram-negative rods

Bacteroides asaccharolyticus

Bacteroides melaninogenicus

Bacteroides fragilis

Bacteroides vulgatus

Total

1
2
3
2
8

Nonspore Gram-positive rods

Propionibacterium acnes

Propionibacterium granulosum

Lactobacillus acidophilus

Lactobacillus fermentum

Lactobacillus $\mathrm{sp}$

Bifidobacterium adolescentis

Eubacterium lentum

Eubacterium sp

Actinomyces odontolyticus

Total

$\begin{array}{r}2 \\ 1 \\ 1 \\ 1 \\ 2 \\ 3 \\ 1 \\ 1 \\ 1 \\ 13 \\ \hline \\ 13 \\ 1 \\ 1 \\ 15 \\ \hline\end{array}$

$C$ perfringens strains were cultured on egg-yolk GAM agar and the colonies suspended in $0.9 \%$ saline solution, then poured into the plates of an API-Strep system.

\section{Results}

Bile samples were obtained from 150 patients, ot $\overrightarrow{\bar{s}}$ which $87(58 \%)$ were culture-positive. Anaerobeso were isolated in 41 cases $(27 \%)$, with a total of 720 strains (Table 1). Among the strains isolated were $\frac{\bar{s}}{7}$ Clostridium (15), Peptostreptococcus (10), Veillonello (10), Peptococcus (8), Bacteroides (8), Streptococcus (7), Lactobacillus (4), Propionibacterium (3), Bifidobacterium (3), Eubacterium (2), and Actinomyces (1)? As Veillonella and Peptostreptococcus exist in the normal oral flora, we thought that these bacteriap might have been mixed with the bile.

We are particularly interested in $C$ perfringens $\dot{\omega}$ especially in those strains which produce $\beta$-glucuronidase. $C$ perfringens was also isolated from $\omega$ bile in 13 cases (Table 2). There was no sex differencer in the incidence, but $C$ perfringens was mostlye isolated from older patients. All of the patients in our study had abdominal pain, fever, and jaundice. The clinical diagnosis of these 13 patients were choledocholithiasis, chronic cholecystitis, gastrie cancer with cholelithiasis, cholelithiasis, choledochate cyst, cholangioma, and suppurative cholangitise Cases SA and JK were urgently sent to our hospitab with acute abdominal pain. SA had repeated pains in the right hypochondrium region with fever anc jaundice. JK had general fatigue with abdominah pain, chills, and jaundice. FK had congenitap choledochal dilation, and had had a chole dochoduodenostomy when she was 17 years old. She had abdominal pain, fever, and jaundice caused by the stricture of the bile duct. Four patients, (TN, NM RI, JK), had choledochal dilation demonstrated by hepatobiliary scintigraphy. Those patients (YS, TS?

Table:2 Cases of Clostridium perfringens isolated from bile

\begin{tabular}{|c|c|c|c|c|c|c|}
\hline Patient & Age (yr) & Sex & Cell dose & Diagnosis & Other isolated organisms & 윽 \\
\hline TN* & 67 & $\mathrm{~F}$ & $+t+$ & Choledocholithiasis & $E$ coli,$+ K$ aerogenes,$+ C$ freundii $(+)$ & \\
\hline NM & 70 & $\mathrm{~F}$ & ++ & Chronic cholecystitis & E coli ++ & 음 \\
\hline $\mathrm{IH}^{*}$ & 73 & M & ++ & Gastric cancer cholelithiasis & $E$ coli.$+++ P$ mirabilis $(+)$ & 三. \\
\hline $\mathrm{YS}^{\dagger}$ & 73 & M & $(+)$ & Chronic cholecystitis & Ecoli $(+)$ & N \\
\hline FK & 34 & $\mathrm{~F}$ & ++ & Choledochal cyst & Ecoli +++ & ת \\
\hline $\mathrm{SA}^{*}$ & 78 & $\mathbf{M}$ & ++ & Cholelithiasis & $\begin{array}{l}\text { E coli }+, K \text { oxytoca }(+), C \text { diversus }(+), \\
\text { Enterococcus }(+)\end{array}$ & ת \\
\hline TS $\div$ & 80 & M & $(+)$ & Cholangioma & $\begin{array}{l}\text { E coli }(+), K \text { aerogenes }++, P \text { mirabilis }(+), \\
\text { Enterococcus }(+), \text { Staph epidermidis }(+)\end{array}$ & $\underline{\omega}$ \\
\hline $\mathrm{KM}^{\dagger} \div$ & 51 & $\mathrm{~F}$ & $(+)$ & Cholelithiasis & None & V \\
\hline $\mathrm{RI}^{*}$ & 65 & $\mathrm{~F}$ & +++ & Choledocholithiasis & E coli,+++ Aeromonas hydrophila ++ & \\
\hline $\mathrm{HT}^{*}$ & 75 & $\mathbf{M}$ & +++ & Choledocholithiasis & Ecoli +++ & \\
\hline $\mathrm{SH}^{*}$ & 73 & $\mathrm{~F}$ & +++ & Choledocholithiasis & E coli,$+++ K$ aerogenes,$+++ K$ oxytoca $(+)$ & $\Phi$ \\
\hline $\mathrm{KI}^{*}$ & 59 & $\mathbf{M}$ & ++ & Gastric cancer cholelithiasis & None & $\stackrel{4}{\rightarrow}$ \\
\hline JK & 71 & M & + & Suppurative cholangitis & Ecoli +++ & Ð \\
\hline \multicolumn{6}{|c|}{$\begin{array}{l}{ }^{*} \text { Bile pigment stone was isolated. } \\
+ \text { Outpatient. } \\
+++=10^{8-9} \text { cells } / \mathrm{ml} \\
++=10^{6-7} \text { cells } / \mathrm{ml} \text {. } \\
+=10^{4-5} \text { cells } / \mathrm{ml} \text {. } \\
(+)=10^{3-4} \text { cells } / \mathrm{ml}\end{array}$} & 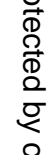 \\
\hline
\end{tabular}


Clostridium perfringens and other anaerobes isolated from bile

Table 3 Serotypes of Clostridium perfringens isolated from bile and the faeces

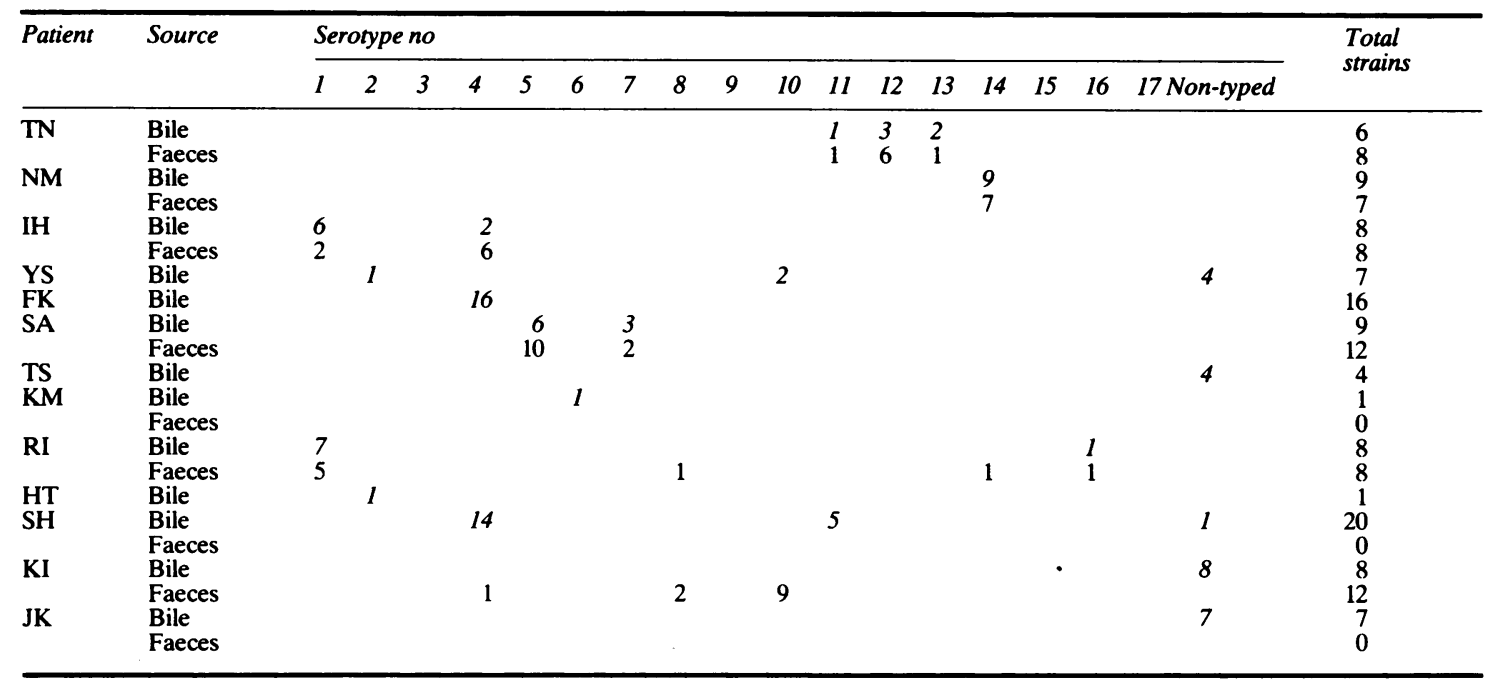

Italic numerals refer to those serotypes isolated from bile.

Table 4 Enzyme production of Clostridium perfringens

\begin{tabular}{|c|c|c|c|c|c|c|c|c|}
\hline Patient & Serotype & $H I P$ & $\beta-G L U$ & $A L P$ & $\beta-G A L$ & PYRA & $G G A$ & ESC \\
\hline TN & 12 & + & + & + & + & + & - & + \\
\hline NM & 14 & + & + & + & + & + & - & + \\
\hline \multirow{2}{*}{ IH } & 1 & + & + & + & + & + & - & - \\
\hline & 4 & + & + & + & + & + & - & - \\
\hline \multirow[t]{3}{*}{ YS } & 2 & + & + & + & + & + & - & - \\
\hline & 10 & + & + & + & + & + & - & - \\
\hline & Non-typed & + & - & + & + & + & - & - \\
\hline FK & 4 & + & + & + & + & + & - & - \\
\hline \multirow[t]{2}{*}{$\mathrm{SA}$} & 5 & + & + & + & + & + & - & + \\
\hline & 7 & + & + & + & + & + & - & + \\
\hline T⿱艹 & Non-typed & + & - & + & + & + & - & - \\
\hline $\mathrm{KM}$ & 4 & + & + & + & + & + & - & - \\
\hline \multirow{4}{*}{ RI } & 1 & + & + & + & + & + & - & + \\
\hline & 8 & + & + & + & + & + & - & + \\
\hline & 14 & + & + & + & + & + & - & + \\
\hline & 16 & + & + & + & + & + & - & + \\
\hline HT & 2 & + & + & + & + & + & - & + \\
\hline \multirow{3}{*}{$\begin{array}{c}\text { SH } \\
, "\end{array}$} & 4 & + & + & + & + & + & - & - \\
\hline & 11 & + & + & + & + & + & - & - \\
\hline & Non-typed & + & - & + & + & + & - & - \\
\hline \multirow[t]{4}{*}{ KI } & 4 & + & + & + & + & + & - & - \\
\hline & 8 & + & + & + & + & + & - & - \\
\hline & 10 & + & + & + & + & + & - & - \\
\hline & Non-typed & + & - & + & + & + & - & - \\
\hline JK & Non-typed & + & - & + & + & + & - & + \\
\hline
\end{tabular}

HIP $=$ hippuric acid hydrolase .

$\beta-G L U=\beta$-glucuronidase.

ALP = alkaline phosphatase.

$\beta$-GAL $=\beta$-galactosidase

PYRA = pyrrolidonylarylamidase

GGA = glycylglycylarylamidase.

$\mathrm{ESC}=\beta$-glucosidase .

KM) with small cell doses ( + ) of $C$ perfringens were outpatients, while all of the others were inpatients. Nine patients (TN, NM, IH, SA, KM, RI, HT, SH, KI) had cholelithiasis demonstrated by ultrasonography of the biliary tract, and seven of them (TN, IH,
SA, RI, HT, SH, KI) were undergoing an elective operation. Bile pigment gallstones were isolated from all seven of the patients.

In the cases with $C$ perfringens, other bacteria isolated at the same time were as follows: 11 cases of 
$E$ coli, three cases of $K$ aerogenes, two cases each of $P$ mirabilis, $K$ oxytoca and Enterococcus, and one case each of $C$ freundii, $C$ diversus, Staph epidermidis, and Aeromonas hydrophila.

When we investigated the serotype of these $C$ perfringens strains using antisera to Hobbs' type 1 to 17 , we found strains of all types except 3,9 , 15 and 17 , and in five cases there were untypable strains. In a single specimen two or more serological types were often found.

As soon as colonies of $C$ perfringens could be detected in the egg-yolk GAM agar from the bile sample, we obtained a faecal sample from the patient, before administering antibiotics, and tried to isolate $C$ perfringens. In the nine cases where faeces were examined, $C$ perfringens was isolated from six patients (Table 3 ). The serotypes of four patients (TN, NM, IH, SA), coincided exactly with the strains isolated from their bile. Extra serotypes 8 and 14 were isolated from the faeces of RI. In the faeces of KI, the serotypes of $C$ perfringens differed from those in the bile. The most frequently isolated strains were four cases of type four, and five cases of non-typed strains.

When we examined $\boldsymbol{\beta}$-glucuronidase production in $C$ perfringens isolated from bile, Hobbs' typed strains were positive and non-typed strains were negative (Table 4).

\section{Discussion}

Bacteria are said to play a major role in the formation of bile pigment calcium stones, ${ }^{2}$ and $E$ coli, Enterococcus, and $C$ perfringens have been isolated from gallstones.' In this study, we investigated the Hobbs' serotype and $\beta$-glucuronidase production in 13 cases of $C$ perfringens isolated from bile.

$C$ perfringens grew rapidly on the egg-yolk agar and was easily isolated from the bile specimens. It could be identified by alpha toxin (lecithinase) production on egg-yolk agar, by stormy fermentation with $10 \%$ Litmus milk, and by degradation of $1 \%$ gelatin, glucose, and lactose.

In the $C$ perfringens strains isolated from bile, two or more serological types were often found in a single specimen and their serotypes differed in each patient (Table 3). However, in the same patient the serotypes coincided well with the strains isolated from the faeces (Table 3). Although $C$ perfringens has been found in all faecal specimens from healthy persons, ${ }^{10}$ we detected the organism also in the bile of our patients.

When the secretion of gastric juice and bile acids was normal, bacteria were not isolated from the bile collected by duodenal aspiration. In our study, $C$ perfringens was isolated from biliary infections such as chronic cholecystitis, cholelithiasis, and suppura-

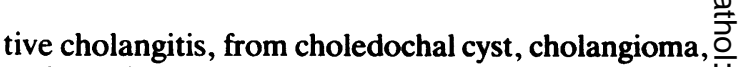
and gastric cancer with cholelithiasis (Table 2). When $\Rightarrow$ we examined the effect of $\mathrm{pH}$ on the growth of $C \stackrel{\vec{T}}{\vec{T}}$ perfringens, we found it grew rapidly above $\mathrm{pH} 5.0$. The growth of $C$ perfringens was inhibited by bile흐 acids. ${ }^{11}$ We think that $C$ perfringens grows if the $\frac{\bar{\rho}}{T}$ normal acid production is suppressed. Forty years $\stackrel{\mathbb{\Phi}}{\varrho}$ ago, it was reported that $C$ perifingens was isolated from patients with lesions of stomach and $\vec{\theta}$ duodenum. ${ }^{12}$

When we examined the $\beta$-glucuronidase $\overrightarrow{\vec{\omega}}$ production of $C$ perfringens, the Hobbs' typed strains $\stackrel{ }{\circ}$ produce $\beta$-glucuronidase but the non-typed strains? did not. It is curious that the Hobbs' typed strains, $\omega$ which cause food poisoning by an endotoxin, all $\omega$ produced $\beta$-glucuronidase, as well.

Another $\beta$-glucuronidase-producing anaerobe $\hat{~} \mathrm{f}$ isolated from bile was Bacteroides fragilis. This strain $ᄋ$ was found by Tharagonnet et al. ${ }^{13}$ The $\mathrm{pH}$ range of the bile was reported to be $6 \cdot 25$ to $8 \cdot 10 .^{1}$ The optimal 3 $\mathrm{pH}$ of tissue $\beta$-glucuronidase is from 4.5 to 5.5 , and above 6.0 its enzyme activity is decreased. ${ }^{14}$ When we $\stackrel{\rho}{\supset}$ examined the optimal $\mathrm{pH}$ of the $\beta$-glucuronidase $\vec{\varphi}$ activity in $E$ coli and $C$ perfringens the former was $6 \cdot 3$, as reported by Buehlar $e t a l^{,}{ }^{3}$ and the latter was $7 \cdot 1$. $E_{0}$ coli produced a $\beta$-glucuronidase maximum at $7-8$ 웅 days, while the rough type of $C$ perfringens produced it at 1-2 days and the smooth type at 3-4 days, continuing its $\beta$-glucuronidase activity for a total of $\frac{\circ}{\Phi}$ two weeks.

As mentioned above, we think that in the case of $C$ perfringens (Hobbs' typed strain) biliary infection, $\beta$-glucuronidase has a significant role in the formation of bile pigment gallstones.

\section{References}

' Tabata M, Nakayama F. Bacteria and gallstones: etiological 0 significance. Dig Dis Sci 1981;26:218-24.

' Maki T. Pathogenesis of calcium bilirubinate gallstone: role of $\frac{D}{O}$ $E$ coli, $\beta$-glucuronidase and coagulation by inorganic ions, polyelectrolytes and agitation. Ann Surg 1966;164:90-100.

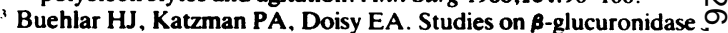
from E coli. Proc Soc Exp Biol Med 1951;76:672-6.

+ Jacox RF. Streptococcal $\beta$-glucuronidase. J Bacteriol 1953;65:700- N 5.

5 Barber M, Brooksbank BWL, Haslewood GAD. Destruction of urinary glucuronide by bacteria. Nature 1948;162:701-2 .

- Kilian M, Bulow P. Rapid identification of Enterobacteriaceae: II. 을 Use of a $\beta$-glucuronidase detecting agar medium (PGUA agar) $\mathbb{D}$ for the identification of $E$ coli in primary cultures of urine ? samples. Acta Pathol Microbiol Scand [B] 1979;87:271-6.

' Hall HE, Angelotti R. Lewis KH. Foter MJ. Characteristics of $\bar{O}$ Clostridium perfringens strains associated with food and food- $\mathbb{D}$ borne disease. J Bacteriol 1963;85: 1094-103.

"Sutton RGA, Hobbs BC. Food poisoning caused by heat-sensitive Clostridium welchii. A report of five recent outbreaks. J Hyg (Camb) 1965;66:135-45. 
${ }^{9}$ Holdeman LV, Moore WEC. Anaerobe laboratory manual. Virginia Polytechnic Institute and State University Anaerobe Laboratory, Blacksburg, Virginia, 1977.

${ }^{10}$ Akama K, Otani S. Clostridium perfringens as the flora in the intestine of healthy persons. Jpn J Med Sci Biol 1970;23:161-75.

" Floch MH, Binder HJ, Filburn B, Gershengoren W. The effect of bile acids on intestinal microflora. Am J Clin Nutr 1972;25:141826.

${ }^{12}$ Quinn WC, Lord JW Jr, Wade LJ. Welchii bacillus infections arising from stomach and duodenum. Surgery 1942;11:229-32.
${ }^{13}$ Tharagonnet D, Sisson PR, Roxby CM, Ingham HR, Selkon JB. The API-Zym system in the identification of Gram-negative anaerobes. J Clin Pathol 1977;30:505-9.

${ }^{14}$ Musa BU, Doe RP, Seal US. Purification and properties of human liver $\beta$-glucuronidase. J Biol Chem 1965;240:2811-6.

Requests for reprints to: Professor K Murata, Department of Clinico-Laboratory Medicine, Kansai Medical University, Moriguchi-shi, Osaka, Japan 570.

\section{The February 1983 issue}

\section{THE FEBRUARY 1983 ISSUE CONTAINS THE FOLLOWING PAPERS}

Infections in British clinical laboratories 1980-81 NR GRIST

Aerosols in the mortuary SWB NEWSOM, CHRISTINE ROWLANDS, JULIE MATTHEWS, CJ ELLIOTT

A modified tetrazolium reaction for identifying malignant cells from gastric and colonic cancer KS IBRAHIM, OAN HUSAIN, L BITENSKY, J CHAYEN

Pepsinogen in gastric carcinoma cells WA REID, WD THOMPSON, J KAY

Cytogenetic studies: an essential part of the paediatric necropsy GR SUTHERLAND, RF CARTER

Nuclear diameter in parathyroid disease SS BANERJEE, B FARAGHER, PS HASLETON

Studies of intestinal lymphoid tissue. VIProliferative response of small intestinal epithelial lymphocyte distinguishes gluten- from nongluten-induced enteropathy MN MARSH, MR HAENEY

A possible route for lymphocyte migration into diseased tissues AJ FREEMONT

Production of a monoclonal antibody reactive with human dendritic reticulum cells and its use in the immunohistologial analysis of lymphoid tissue M NAIEM, J GERDES, Z ABDULAZIZ, H STEIN, DY MASON

Assessment of cellularity in bone marrow fragments AN AL-ADHADH, I CAVILL

Marrow cellularity in the diagnosis of polycythaemia NP LUCIE, GAR YOUNG

Comparison of haematological indices between women of four ethnic groups and the effect of oral contraceptives IF GODSLAND, MARY SEED, RUTH SIMPSON, G BROOM, $\mathrm{V}$ WYNN

A comparison of peripheral blood and buffy coat smear examination for the prediction of bone marrow relapse of acute lymphoblastic leukaemia in childhood IM FRANKLIN
"New" lectins for the identification of erythrocyte cryptantigens and the classification of erythrocyte polyagglutinability: Medicago disciformis and Medicago turbinata GWG BIRD, JUNE WINGHAM

Immunohistochemical localisation of thrombospondin in human megakaryocytes and platelets KATHRYN M MCLAREN

Low pancreatic lipase in insulin-dependent diabetics D JUNGLEE, R DE ALBARRAN, A KATRAK, DB FREEDMAN, AG BECKETT, P DANDONA

Early time course of the acute phase protein response in man CM COLLEY, A FLECK, AW GOODE, BR MULLER, MA MYERS

Semiautomated determination of minimum bactericidal concentrations of antibiotics F O'GRADY, BARBARA MURPHY, NJ PEARSON

The pathogenic potential of commensal species of Neisseria AP JOHNSON

Do urethral Escherichia coli cause abacterial cystitis? P WALPITA, FP MARSH

Comparison of enzyme-linked immunosorbent assay (ELISA) and complement fixation test for detection of Mycoplasma pneumoniae antibodies ELIZABETH DUSSAIX, A SLIM, P TOURNIER

Influence of sample preparation on estimates of blood fibronectin concentration MARGARET BOWEN, T MÜLLER

Measurement of conjugated and unconjugated serum bile acid concentrations using $3 \alpha$-hydroxysteroid dehydrogenase SM SMITH, M MYSZOR, KDR SETCHELL, GM MURPHY

\section{Letters to the Editor}

Book reviews

Notices

Some New Titles

Copies are still available and may be obtained from the the PUBLISHING MANAGER, BRITISH MEDICAL ASSOCIATION, TAVISTOCK SQUARE, LONDON WC1H 9JR, price $£ 5 \cdot 00$, including postage 